\title{
Avaliação da qualidade de águas de chuva armazenadas em cisternas de placas e de polietileno em um município do semiárido do estado da Paraíba
}

\author{
Evaluation of rainwater quality stored in cisterns of concrete plates and \\ polyethylene in a municipality in the semi-arid of the Paraiba State
}

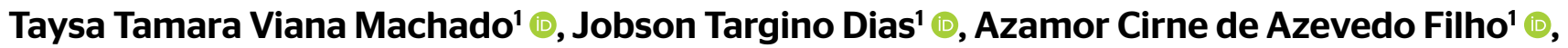

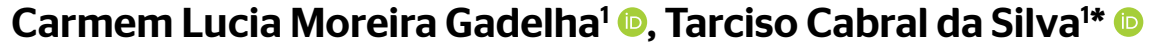

\begin{abstract}
RESUMO
Neste trabalho é apresentada uma avaliação das águas de chuva armazenadas em cisternas no semiárido do estado da Paraíba. Foram coletadas e analisadas amostras de água de cisternas de placas de concreto (CPLA) e de polietileno (CPOL), buscando-se verificar se há diferenças entre os parâmetros de qualidade da água nos dois tipos de cisternas. Foram aplicados testes estatísticos para detectar se há diferenças entre os parâmetros físico-químicos pH, temperatura, turbidez, condutividade elétrica, sólidos totais dissolvidos, oxigênio dissolvido, alcalinidade, cor, dureza, cloreto, amônia, sulfato, salinidade e nitrato. Também foram feitas análises da variabilidade dos parâmetros e verificações de conformidade de acordo com a Portaria no 5/2017 do Ministério da Saúde que estabelece os padrões de potabilidade da água. Entre os parâmetros analisados nas amostras de água provenientes das CPLA e CPOL, os que apresentaram confirmação da hipótese de igualdade de médias foram cloreto, oxigênio dissolvido e sulfato. Houve maior variabilidade da alcalinidade e da salinidade nas águas das CPLA em relação às das CPOL. Quase todos os parâmetros físico-químicos apresentaram-se em conformidade com a portaria, com exceção de cor, pH e turbidez.
\end{abstract}

Palavras-chave: cisternas de placas de concreto; cisternas de polietileno; qualidade da água de chuva; semiárido.

\begin{abstract}
An evaluation of rainwater stored in cisterns in the semiarid region of the state of Paraíba is presented in this paper. Water samples from concrete plates cisterns (CPLAs) and polyethylene ones (CPOLs) were collected and analyzed in order to verify whether there are differences between water quality parameters in the two types of cisterns. Statistical tests were applied to detect whether there are differences between the physical and chemical parameters $\mathrm{pH}$, temperature, turbidity, electrical conductivity, total dissolved solids, dissolved oxygen, alkalinity, color, hardness, chloride, ammonia, sulfate, salinity, and nitrate. Analyses of the variability of the parameters and verifications of compliance were also carried out in accordance with the Ministry of Health Consolidation Ordinance 05/2017, which establishes water potability standards. Among the parameters analyzed in the water samples from the CPLAs and CPOLs, those that confirmed the hypothesis of equality of means were chloride, dissolved oxygen, and sulfate. There were higher alkalinity and salinity variability in CPLAs waters in relation to these parameters in CPOLs. Almost all physicochemical parameters were in compliance with the ordinance, and the exception were color, $\mathrm{pH}$, and turbidity.
\end{abstract}

Keywords: concrete plates cisterns; polyethylene cisterns; rainwater quality; semiarid.

'Universidade Federal da Paraíba - João Pessoa (PB), Brasil.

*Autor correspondente: tarcisocabral@gmail.com

Conflitos de interesse: os autores declaram não haver conflito de interesses.

Financiamento: Conselho Nacional de Desenvolvimento Científico e Tecnológico (CNPq) (Edital Universal 14/2013 - Processo CNPq no 477785/2013-1) e Coordenação de Aperfeiçoamento de Pessoal de Nível Superior (CAPES).

Recebido: 04/06/2018 - Aceito: 21/11/2019 - Reg. ABES: 20180003 


\section{INTRODUÇÃO}

Milhões de pessoas usam sistemas alternativos para o suprimento de água, visando ao consumo e às atividades humanas. Entre eles são destacados os sistemas de captação e armazenamento de água de chuva (SCAAC), cujo uso teve aumento de duas vezes no período de 1990 a 2010, no campo e nas cidades (KWAADSTENIET et al., 2013).

Em países como Alemanha, Japão, Estados Unidos, China, Nova Zelândia, Tailândia, México e Austrália, têm-se adotado vários modelos de cisternas para o armazenamento da água de chuva, viabilizando o seu uso posterior (SANTOS et al., 2009; GOMES et al., 2014).

No Brasil, o uso de SCAAC ocorre há séculos. No entanto, para o meio rural, foi somente a partir do ano de 2003 que passaram a existir programas governamentais abrangentes, que propiciam a disseminação dessa forma de armazenamento de água (ANDRADE NETO, 2013; MACHADO; DIAS; SILVA, 2017).

No semiárido brasileiro $(\mathrm{SAB})$, onde ocorrem um período curto, de três a quatro meses, com precipitações pluviométricas, e outro longo, sem a ocorrência de eventos chuvosos significativos, a captação de água de chuva e o armazenamento em cisternas é uma alternativa considerada essencial, por permitir o abastecimento para o atendimento aos seus moradores (SOUZA et al., 2011).

A introdução das medidas de convivência no semiárido baseia-se na ênfase sobre a criação de possibilidades de uso sustentável dos recursos naturais, em que o armazenamento da água das chuvas nas cisternas visa oferecer segurança hídrica para o consumo doméstico. Trata-se de uma nova visão no SAB, na qual se busca a adequação tecnológica a uma natureza distinta das zonas úmidas (MACHADO, 2017).

O Programa de Formação e Mobilização Social para Convivência com o Semiárido: Um Milhão de Cisternas Rurais (P1MC) surgiu pela iniciativa da Articulação Semiárido (ASA) em 1999, tendo sido incluído no programa Fome Zero do Governo Federal em 2003, com a finalidade de atender às populações difusas residentes nas áreas rurais do SAB (NÓBREGA et al., 2012). De acordo com o P1MC, uma cisterna de 16 mil litros de capacidade é suficiente para atender ao consumo de água para beber e cozinhar de uma família com cinco pessoas, durante o período de oito meses.

Com objetivos semelhantes, foi instituído no ano de 2011 o Programa Nacional de Universalização do Acesso e Uso da Água - Água para Todos. Para acelerar a instalação das cisternas, introduziram-se, nesse programa, as fabricadas em polietileno, também com 16 mil litros de capacidade. Assim, até o ano de 2016, já foram instaladas mais de 1,2 milhão de cisternas de placas e de polietileno no SAB, no âmbito dos programas P1MC e Água para Todos (MACHADO; DIAS; SILVA, 2017).

Diversos estudos desenvolvidos no Brasil têm demonstrado que houve impactos positivos na saúde humana e na qualidade de vida decorrentes do acesso aos programas de aproveitamento de água de chuva, muito embora tenha sido demonstrado em alguns deles que os efeitos na saúde poderiam ser ampliados caso cuidados adicionais e ações fossem adotados, sobretudo aqueles relacionados a melhores práticas de higiene e manuseio da água (LUNA, 2011; SILVA et al., 2012; FONSECA, 2012; SILVA; HELLER; CARNEIRO, 2012; FONSECA et al., 2014; GOMES; HELLER, 2016). Nesse sentido, a influência do manejo das cisternas, particularmente a existência de barreiras sanitárias, sobre a qualidade da água de chuva armazenada para múltiplos usos tem sido objeto de investigação de pesquisadores, em seus parâmetros físicos, químicos e/ou biológicos (PALHARES; GUIDONI, 2012; VIRIATO, 2011; XAVIER, 2010).
Vários estudos realizados sobre água de chuva em cisternas indicaram que, em geral, sua qualidade atende aos padrões de potabilidade da Organização Mundial da Saúde para os parâmetros físicos e químicos, porém para padrão microbiológico frequentemente se encontravam em desacordo. Isso significa que a água poderia estar contaminada ou susceptível à contaminação por microrganismos patogênicos (GOULD; NISSEN-PETERSEN, 2002; VIDAL, 2002; ALVES et al., 2012; ANDRADE NETO, 2013).

A Portaria Consolidada (PCR) nº 5/2017 do Ministério da Saúde (BRASIL, 2017) que se refere à consolidação das normas sobre as ações e os serviços de saúde do Sistema Único de Saúde, no Anexo XX, dispõe sobre o controle e a vigilância da qualidade da água para consumo humano e seu padrão de potabilidade. Aplica-se às águas destinadas ao consumo humano provenientes de sistemas e soluções alternativas de abastecimento. Assim, relativamente a essa Portaria, pesquisas realizadas têm mostrado a não conformidade das águas armazenadas nas cisternas do programa P1MC, para alguns parâmetros de qualidade (SILVA, 2006; TAVARES, 2009; FONSECA, 2012; GOMES; HELLER, 2016).

Para Alves et al. (2012), que monitoraram sete cisternas localizadas no SAB durante quatro anos, diversos fatores exercem influência na qualidade da água, como o tipo de reservatório e os materiais usados na sua construção. Ceballos et al. (2014) observaram problemas na qualidade da água associados às condições físicas das cisternas monitoradas em comunidades rurais dos municípios de São João do Cariri e Campina Grande, no estado da Paraíba.

Existe uma razoável quantidade de estudos e pesquisas sobre SCAAC, principalmente nas últimas décadas do século XX (GNADLINGER, 2015), incluindo a qualidade das águas armazenadas em cisternas. No entanto, as cisternas de polietileno, utilizadas em larga escala apenas recentemente, têm sido alvo de críticas, com relatos de questionamentos e polêmicas e, apesar disso, contam com poucos estudos dedicados à verificação da adequação dos parâmetros de qualidade da água, considerando os padrões de potabilidade (SCHMITT, 2015; MOURA et al., 2017). Também são praticamente inexistentes na literatura brasileira investigações relativas à comparação entre os parâmetros de qualidade da água armazenada em cisternas de placas e de polietileno (MACHADO, 2017).

Na pesquisa realizada nos órgãos de gestão de recursos hídricos e de saúde pública foi constatado que não há programa de monitoramento como ação permanente do governo ou de instituições privadas sobre a qualidade da água nas cisternas no semiárido.

Neste trabalho, faz-se uma avaliação comparativa da qualidade da água armazenada nas cisternas de placas e de polietileno em um município no semiárido do estado da Paraíba. O principal objetivo é verificar se há diferenças significativas entre parâmetros de qualidade da água de chuva armazenada nos dois tipos de cisternas. Os resultados obtidos podem revelar a influência do tipo do material constituinte das cisternas (placas de concreto ou de polietileno) nos parâmetros analisados. Também são realizadas análises sobre a variabilidade dos conjuntos de dados obtidos, dos parâmetros físicos e químicos, destacando a dispersão, a simetria e a existência de valores discrepantes. Finalmente, realiza-se a avaliação da conformidade dos parâmetros de qualidade em relação à PCR n ${ }^{\circ}$ 5/2017.

\section{METODOLOGIA}

Para a análise da qualidade da água de chuva armazenada em cisternas de placas de concreto (CPLA) e de polietileno (CPOL), ilustradas na Figura 1, foram feitas 


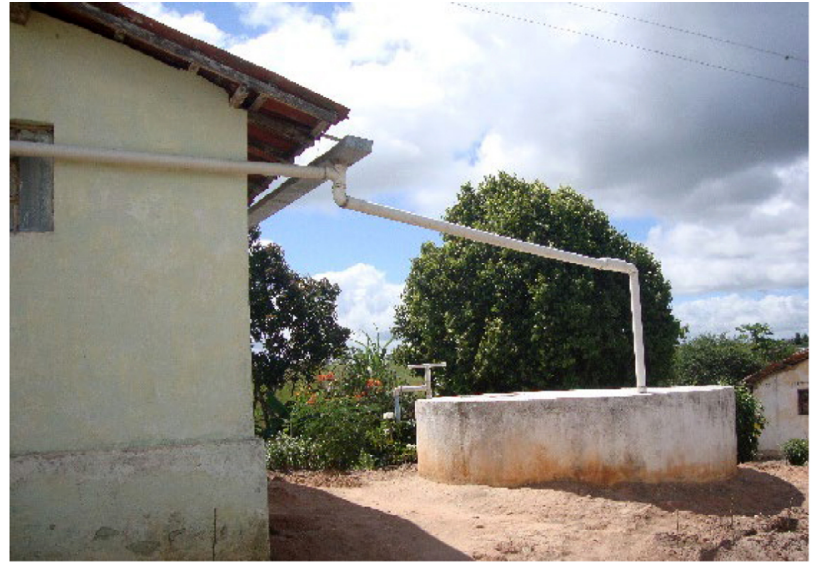

A

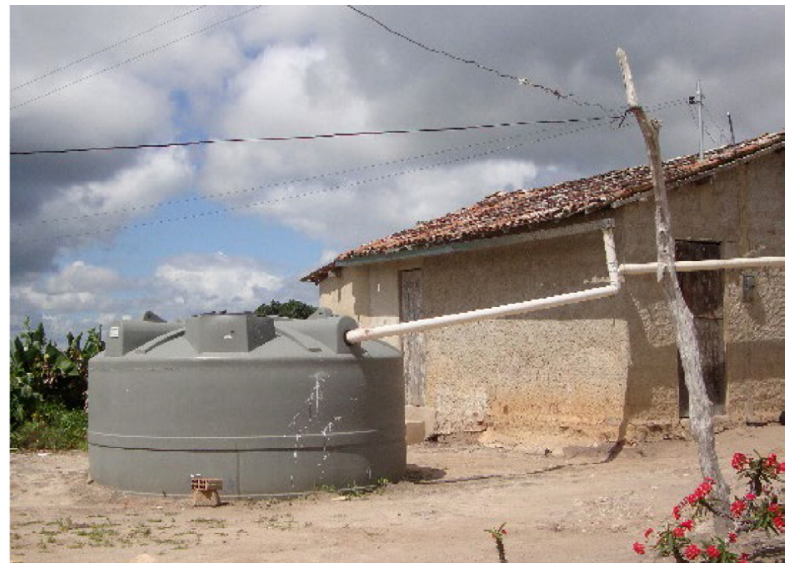

B

Fonte: acervo da pesquisa (2018)

Figura 1 - (A) Cisterna de placas e (B) cisterna de polietileno.

coletas em três comunidades rurais no município de São Sebastião de Lagoa de Roça, na região do semiárido do estado da Paraíba, localizado na mesorregião do Agreste Paraibano (Figura 2). Esse município apresenta altitude média de $641 \mathrm{~m}$, temperatura média anual de $24^{\circ} \mathrm{C}$ e precipitação média anual de $828 \mathrm{~mm} / \mathrm{ano}$. O clima, segundo a classificação de Köppen, é As, clima tropical com estação seca. O município possuía população de 11.041 habitantes, de acordo com o último censo realizado (IBGE, 2010), e tem sua economia baseada na agricultura. Comunidades rurais como essa não dispõem de sistemas públicos ou privados relativos a redes de distribuição de água e de esgotamento sanitário.

As amostras de água foram coletadas em oito CPLA e seis CPOL com frequência mensal, no período de outubro de 2015 a outubro de 2016. Foram feitas 2.285 análises, contemplando os 14 parâmetros já referidos, sendo 1.306 de água das CPLA e 979 de água das CPOL. Os parâmetros alcalinidade, amônia, cloretos, cor e dureza tiveram maior número de análises (95) nas CPLA. O de menor número foi nitrato (66) nas CPOL. Os critérios estabelecidos para a escolha das cisternas foram: utilização de sua água para consumo humano e ausência de mistura de água de chuva com água de açude na cisterna.

Em todas as cisternas selecionadas as informações dos usuários davam conta de que se realizava o desvio das primeiras águas das chuvas no telhado de captação, o que é um indicativo das melhores condições de qualidade da água armazenada. Também havia bombas hidráulicas para a captação de água para o consumo, o que revelava boas práticas no sentido de se obter água de melhor qualidade para as famílias.

Os parâmetros $\mathrm{pH}$, temperatura, turbidez, condutividade elétrica (CE), salinidade, sólidos totais dissolvidos (TDS) e oxigênio dissolvido (OD) foram medidos in loco por meio de sonda multiparamétrica. Já para a determinação de alcalinidade, cor, dureza, cloretos, amônia, sulfato e nitrato, amostras de um litro foram coletadas e levadas, devidamente refrigeradas, para a realização das análises nos laboratórios da Universidade Federal da Paraíba (UFPB) em João Pessoa, de acordo com os procedimentos descritos por APHA, AWWA e WEF (2012).

Para a verificação das diferenças entre as médias de cada parâmetro de qualidade analisado da água armazenada nas CPLA e CPOL, foram utilizados testes estatísticos de comparação de médias, envolvendo os valores medidos de cada um dos parâmetros analisados. Foram eles o teste $t$ de Student para amostras com distribuição normal e o U de Mann-Whitney, se a distribuição fugia à normalidade. As hipóteses dos testes para a comparação de médias foram formuladas como: $\mathrm{H} 0$ - as amostras são provenientes de uma mesma população, ou seja, as médias são iguais; $\mathrm{H} 1$ — as amostras não são provenientes de uma mesma população, ou seja, as médias não são iguais. A hipótese nula não é rejeitada quando p é maior que o nível de significância. Os testes foram realizados com nível de significância $\alpha$ de 5\%, utilizando-se o software Statistical Package for the Social Sciences 20 (SPSS 20).

A análise da variabilidade dos conjuntos de dados obtidos nos parâmetros físicos e químicos foi realizada utilizando-se gráficos tipo boxplot, com destaque para a dispersão, a simetria e a existência de valores discrepantes. A variabilidade dos dados é representada pela diferença entre os quartis Q3 e Q1 (ARAÚJO; ABAR, 2012).

Também foram feitas comparações entre os valores dos parâmetros de qualidade analisados na água armazenada nos dois tipos de cisternas, conforme os padrões estabelecidos pela PCR no 5/2017 para consumo humano, observando-se os valores máximos e mínimos permitidos. A avaliação foi feita por meio do cálculo dos percentuais de conformidade desses parâmetros em relação aos valores preconizados pela referida Portaria. Deve ficar claro que a água apropriada para o consumo humano seria a que apresenta $100 \%$ das amostras em conformidade com esses valores.

\section{RESULTADOS E DISCUSSÃO}

Os resultados das análises efetuadas, relativos aos parâmetros estatísticos correspondentes à água de chuva armazenada nas cisternas de placas e de polietileno, estão apresentados nas Figuras 3 e 4.

Os gráficos do tipo boxplot construídos com base nos conjuntos dos valores dos parâmetros de qualidade da água nos quais houve rejeição da hipótese de igualdade de média $(\mathrm{p} \leq 0,005)$, constam na Figura 3. Os parâmetros 


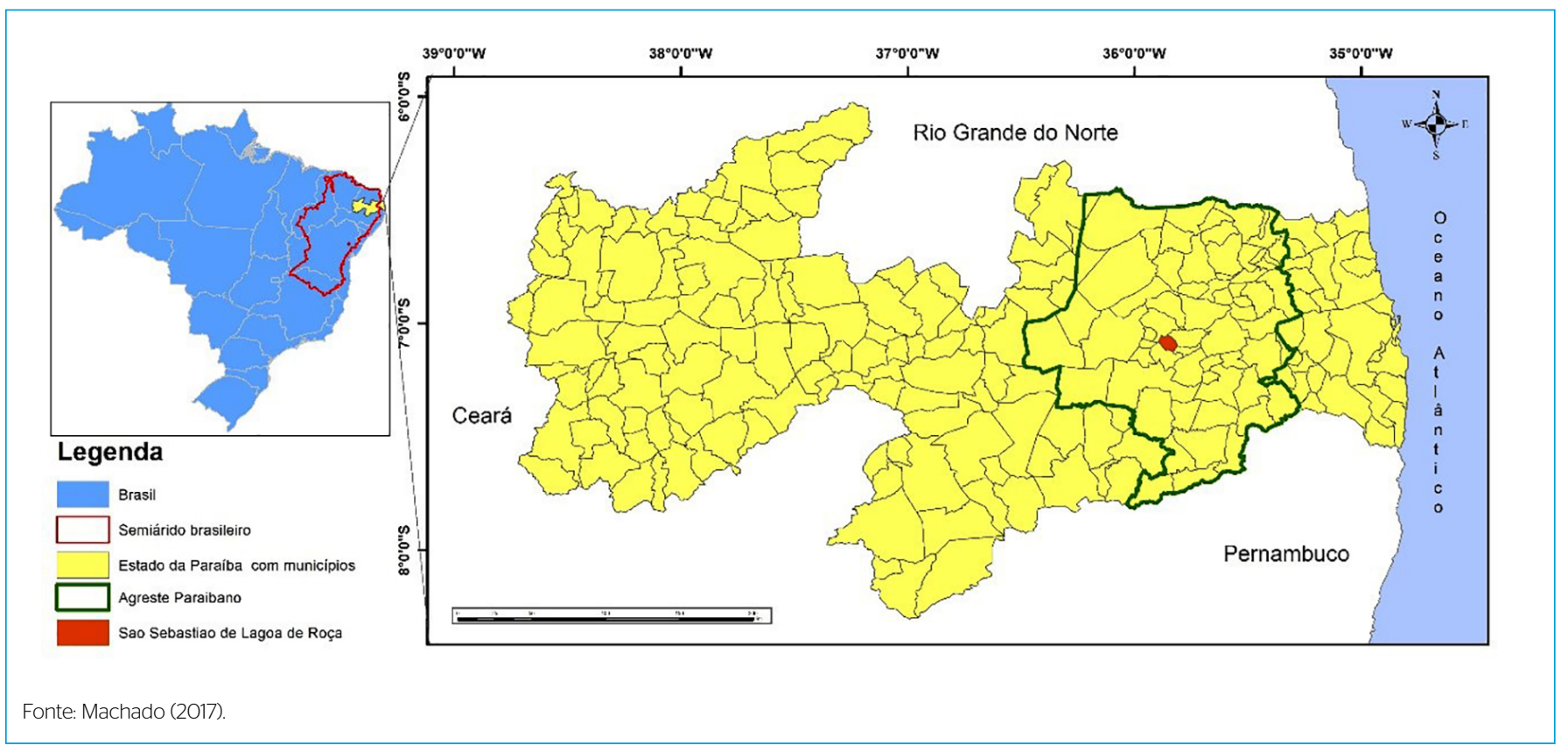

Figura 2 - Localização do município de São Sebastião de Lagoa de Roça.

alcalinidade, $\mathrm{CE}$, salinidade, $\mathrm{OD}$ e temperatura não estão referidos com limites relativos a valor máximo permitido (VMP) na PCR nº 5/2017.

O exame dos gráficos da Figura 3 indicou que os parâmetros de qualidade da água armazenada nas cisternas de placas e de polietileno que tiveram resultados de comparação de médias com a hipótese $\mathrm{H} 0$ rejeitada foram alcalinidade, amônia, CE, cor, dureza, $\mathrm{pH}$, salinidade, sulfato e TDS.

Verificaram-se também, na Figura 3, maiores valores das medianas para os parâmetros alcalinidade, $\mathrm{CE}$, dureza, $\mathrm{pH}$, salinidade, sulfato e TDS da água das cisternas de placas. Apenas as distribuições no intervalo interquartílico dos parâmetros amônia, $\mathrm{CE}, \mathrm{pH}$, sulfato e TDS das águas armazenadas nas CPLA estão indicadas nos gráficos como simétricas.

Foram observadas maiores variabilidades dos parâmetros alcalinidade e salinidade nas águas das CPLA em relação aos das águas das CPOL. Cor, amônia e dureza apresentaram maior variabilidade nas águas das cisternas de polietileno em relação às de placas. Os valores máximos dos parâmetros ocorreram sempre nos gráficos em que as medianas foram maiores. Por outro lado, os valores mínimos ocorreram sempre nos gráficos em que as medianas foram menores.

Foi possível constatar a ocorrência de outliers nos parâmetros amônia, CE, cor, salinidade e TDS, que apresentaram pontos acima dos valores máximos nas cisternas. Os parâmetros CE e TDS apresentaram pontos abaixo dos valores mínimos nas CPLA. Valores extremos, todos acima dos pontos máximos, foram verificados nos gráficos dos parâmetros CE e TDS na água das cisternas de placas (Figura 3).

A Figura 4 apresenta os gráficos de tipo boxplot relativos aos valores dos parâmetros de qualidade da água medidos nas cisternas de placas e de polietileno nos quais não houve rejeição da hipótese de igualdade de médias ( $p>0,005)$. Pode ser observado que os parâmetros cloreto, nitrato, OD, temperatura e turbidez apresentaram resultados da comparação de médias com a hipótese H0 não rejeitada.
Ficou claro que não houve, como esperado, diferenças expressivas entre os valores das medianas dos parâmetros de qualidade nas águas das cisternas de placas e de polietileno. Apenas as distribuições no intervalo interquartílico do parâmetro OD das águas armazenadas nas CPLA estão indicadas no gráfico como simétricas. Houve maiores variabilidades dos parâmetros temperatura, OD e turbidez nas CPLA comparativamente às CPOL. Os valores máximos dos parâmetros foram observados na maioria dos gráficos nos quais as medianas foram maiores, nos dois tipos de cisternas. As exceções ocorreram para o parâmetro nitrato, no qual os valores máximos ocorreram no conjunto de dados que apresentou as medianas menores. Os valores mínimos ocorreram sempre para os parâmetros nos quais as medianas foram menores, com exceção do OD, nas águas das cisternas de polietileno (Figura 4).

Foram verificadas ocorrências de outliers nos parâmetros nitrato e temperatura, ambos com pontos acima dos valores máximos das águas das $\mathrm{CPOL}$ e CPLA, respectivamente. Valores extremos, todos acima do ponto máximo, foram verificados para os parâmetros cloreto e nitrato nas águas das cisternas de placas e turbidez nas de polietileno. Para a temperatura, o ponto extremo ocorreu abaixo do valor mínimo (Figura 4).

Em relação à variabilidade temporal dos parâmetros de qualidade da água armazenada nas cisternas, não foram identificadas alterações expressivas. Também não se observaram tendências negativas ou positivas nas séries temporais dos valores medidos de cada parâmetro no período analisado, praticamente coincidente ao ano hidrológico 2015/2016.

Dos parâmetros físicos e químicos analisados, na água das CPLA, apenas a turbidez e a cor não apresentaram conformidade com a PCR nº 5/2017, em todas as medições, com frequências percentuais de 92,39 e 90,53\%, respectivamente. Com relação à água das $\mathrm{CPOL}$, a cor, o $\mathrm{pH}$ e a turbidez não apresentaram conformidade em relação à Portaria, com frequências percentuais de 82,86, 74,65 e $97,18 \%$, respectivamente. 

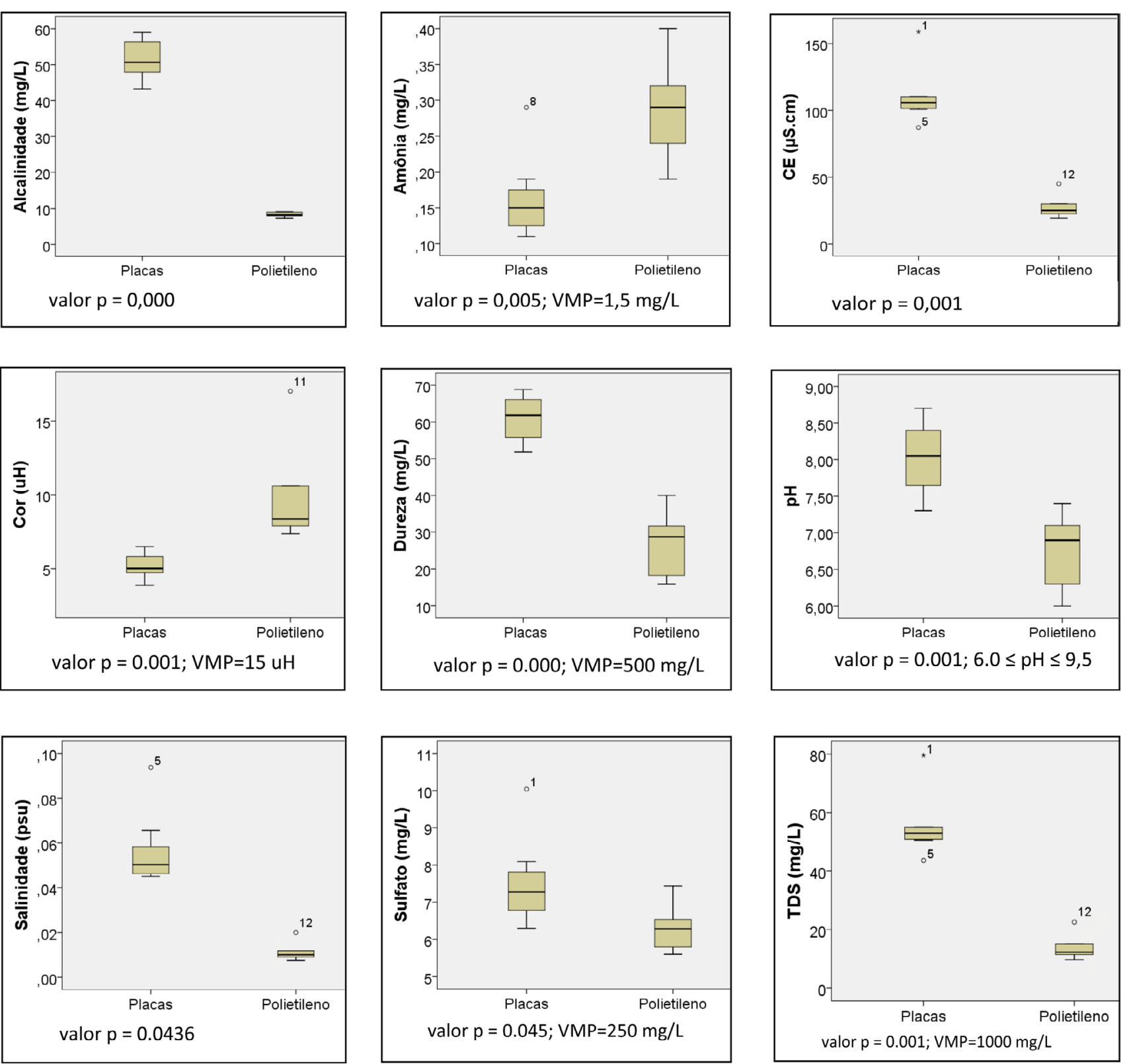

VMP: valor máximo permitido; CE: condutividade elétrica; TDS: sólidos totais dissolvidos. Fonte: Machado (2017).

Figura 3 - Parâmetros com rejeição da hipótese HO de igualdade de média, p e valor máximo permitido.

Entre os parâmetros que não estavam em conformidade com a PCR $n^{\circ} 5 / 2017$, nos dois tipos de cisternas, a turbidez pode ser explicada pela ausência de limpeza da área de captação das águas de chuva e pelo carreamento de sólidos sedimentados no telhado, além da limpeza deficiente das cisternas e pela falta de desvio das águas das primeiras chuvas.

A coloração da água deve ter sido alterada pela presença de sólidos dissolvidos, principalmente, material orgânico e inorgânico em solução. Esses sólidos também alteram outras características organolépticas das águas, que podem se apresentar salobras ou salinas. No entanto, deve ser observado que a cor não é, necessariamente, relacionada com problemas de contaminação (PIVELI; KATO, 2005).

Um aspecto relevante a considerar com relação aos parâmetros turbidez e cor diz respeito ao aporte da água de chuva nas cisternas, que pode ressuspender o material sedimentado no fundo, alterando, em consequência, seus valores.

A não conformidade do parâmetro turbidez, nos dois conjuntos de cisternas, não deve ser um fato gerador de preocupações, haja vista que as médias dos valores foram bastante inferiores ao VMP da PCR no 5/2017. Os valores obtidos para a turbidez estão, no geral, em concordância com os de outros 

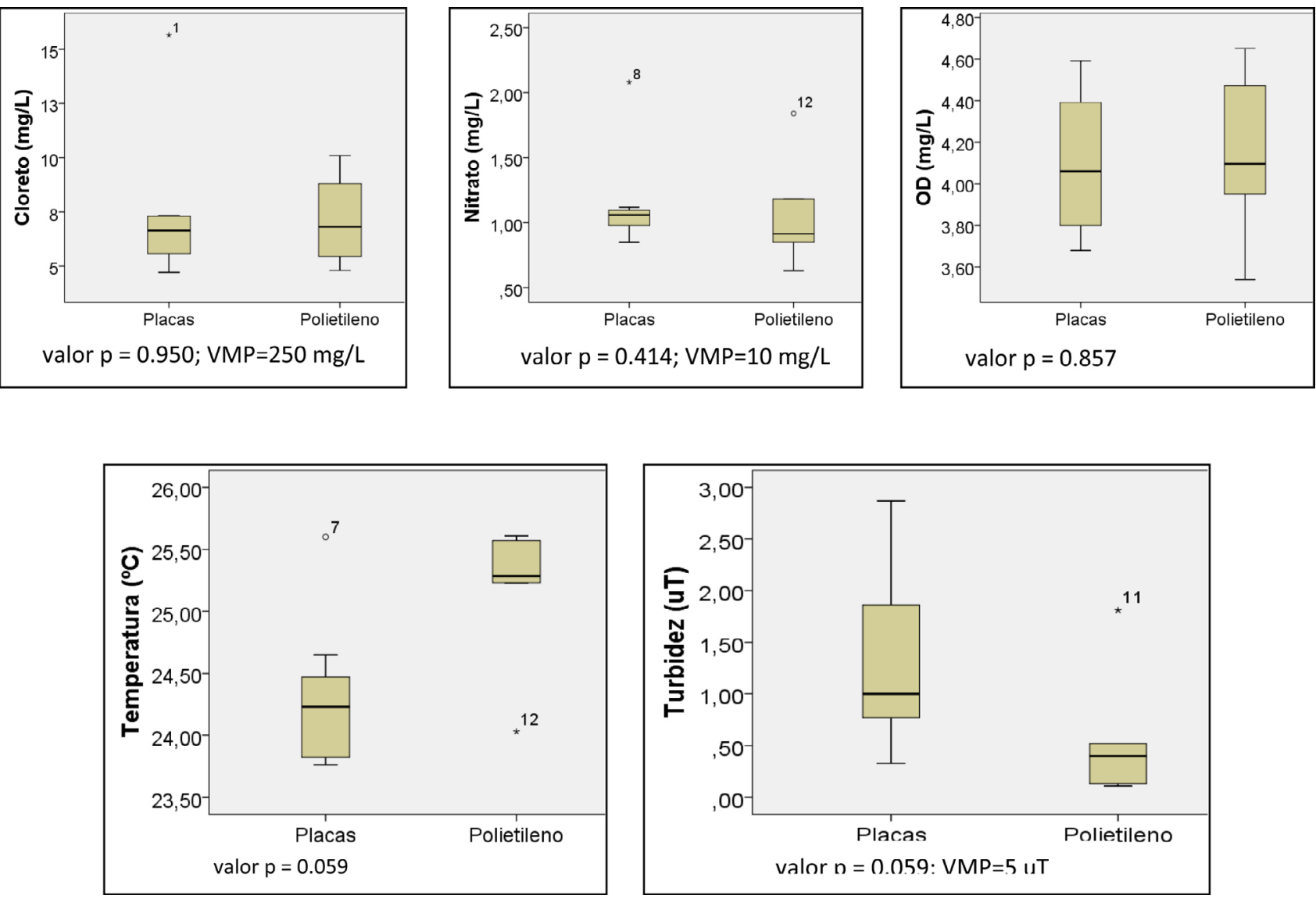

VMP: valor máximo permitido; OD: oxigênio dissolvido. Fonte: Machado (2017).

Figura 4 - Parâmetros sem rejeição da hipótese HO de igualdade de média, p e valor máximo permitido.

pesquisadores. Viriato (2011), no seu trabalho sobre caracterização física, química e bacteriológica das águas armazenadas em 12 CPLA na Paraíba, obteve medições de turbidez variando de 0,87 a 4,95 uT.

Também foi possível verificar que o parâmetro $\mathrm{pH}$ só não se apresentou em conformidade com a PCR no 5/2017 para as cisternas de polietileno, com valores abaixo do VMP, fazendo com que a água armazenada fosse classificada como ácida. Esse resultado pode ser explicado pela acidez natural da água de chuva (SANTANA, 2012) e também pela característica do material (polietileno) das cisternas, considerado quimicamente inerte. No caso das cisternas de placas, o material constituinte (concreto) tende a diminuir a acidez da água armazenada (HAGEMANN, 2009).

De acordo com Cohim, Orrisco e Kieronski (2015), a literatura científica aponta para uma elevação do valor do $\mathrm{pH}$ e da alcalinidade da água de chuva após seu contato com a superfície de captação e posterior armazenamento nas cisternas de placas.

Embora não seja citada como parâmetro de conformidade na PCR nº 5/2017, a temperatura deve ser destacada nas análises da água, uma vez que influencia quase todos os processos físicos, químicos e biológicos que ocorrem no meio aquático (VIEIRA, 2016). No presente caso, foram verificadas pequenas diferenças não significativas entre as médias dos valores da temperatura entre a água armazenada nas CPLA e CPOL, mais elevados nas CPOL.

\section{CONCLUSÕES}

Considerando-se que o principal objetivo deste trabalho foi realizar uma avaliação comparativa da qualidade das águas de chuva armazenadas nas cisternas, com destaque para o tipo de material de sua constituição, placas de concreto ou polietileno, os resultados indicaram que, em 10 dos 14 parâmetros físicos e químicos analisados, quais sejam, alcalinidade, amônia, $\mathrm{CE}$, cor, dureza, $\mathrm{pH}$, salinidade, sulfato e TDS, não foi possível concluir que suas médias para os dois tipos de cisternas foram iguais. Por conseguinte, pode-se inferir, de fato, que há influência dos materiais constituintes das cisternas na qualidade da água armazenada.

Sobre a variabilidade da distribuição dos dados, abrangendo simetria, dispersão e a existência de valores discrepantes, pode-se concluir que houve maiores variabilidades dos parâmetros alcalinidade e salinidade nas águas das CPLA em relação aos das águas das CPOL. Por outro lado, os parâmetros cor, amônia e dureza apresentaram maior variabilidade nas águas das cisternas de polietileno em relação às de placas de concreto. Os maiores valores das medianas dos 
parâmetros medidos ocorreram nos gráficos em que houve valores máximos. De outro modo, os valores mínimos ocorreram sempre nos gráficos nos quais as medianas foram menores. Apenas as distribuições no intervalo interquartílico dos parâmetros amônia, $\mathrm{CE}, \mathrm{pH}$, sulfato, OD e TDS das águas armazenadas nas CPLA estão indicadas nos gráficos como simétricas.

Quanto à análise dos parâmetros em relação aos padrões estabelecidos pela PCR no 5/2017 do Ministério da Saúde, nas cisternas de placas e de polietileno, a cor e a turbidez não se mostraram em conformidade. Para o parâmetro $\mathrm{pH}$ não houve atendimento à Portaria na água das cisternas de polietileno, o que deve ser justificado pela acidez natural da água de chuva e pelo tipo de material, considerado como quimicamente inerte.

A água de chuva armazenada em cisternas e o seu uso para o consumo humano tem-se constituído em uma alternativa viável para a convivência na região do semiárido. No entanto, é necessário que as águas sejam bem manuseadas e tratadas a fim de proteger a saúde da população e de que elas não se tornem um veículo de transmissão de doenças.

\section{CONTRIBUIÇÕES DOS AUTORES}

Machado, T. T. V.: Conceituação, Curadoria de Dados, Investigação, Metodologia, Supervisão, Escrita - Primeira Redação. Silva, T. C.: Conceituação, Análise Formal, Obtenção de Financiamento, Metodologia, Administração do Projeto, Recursos, Software, Supervisão, Visualização, Escrita - Revisão e Edição. Dias, J. T.: Curadoria de Dados, Investigação, Escrita - Primeira Redação. Azevedo Filho, A. C.: Curadoria de Dados, Análise Formal, Validação, Visualização. Gadelha, C. L. M.: Análise Formal, Validação, Escrita - Revisão e Edição.

\section{REFERÊNCIAS}

ALVES, F.; LUZ, J.; FIGUEIRAS, M.L.; MEDEIROS, L.L.; SANTOS, S.M.; GAVAZZA, S. Qualidade de água em cisternas do semiárido pernambucano. In: SIMPÓSIO BRASILEIRO DE CAPTAÇÃO E MANEJO DE ÁGUA DE CHUVA, 8., 2012. Anais [...]. Campina Grande, 2012.

AMERICAN PUBLIC HEALTH ASSOCIATION (APHA); AMERICAN WATER WORKS ASSOCIATION (AWWA); WATER ENVIRONMENT FEDERATION (WEF). Standard methods for the examination of water and wastewater. 22a ed. Washington, D.C.: APHA/AWWA/WEF, 2012.

ANDRADE NETO, C.O. Aproveitamento imediato da água de chuva. Revista Eletrônica de Gestão e Tecnologia Ambientais, v. 1, n. 1, p. 73-86, 2013. http:// dx.doi.org/10.17565/gesta.v1i1.7106

ARAÚJO, P.C.; ABAR, C.A.A.P. Sobre O Boxplot no GeoGebra. In: CONFERÊNCIA LATINO-AMERICANA DE GEOGEBRA, 1., 2012. Anais [...]. São Paulo, 2012. p. 13-21.

BRASIL. Ministério da Saúde. Portaria de Consolidação no 5, de 28 de setembro de 2017. Dispõe sobre a consolidação das normas sobre as ações e os serviços de saúde do Sistema Único de Saúde. Diário Oficial [da República Federativa do Brasil], Brasília, n. 190, Seção 1, p. 360, 3 out. 2017.

CEBALLOS, B.S.O.; XAVIER, R.P.; NÓBREGA, R.L.B.; GALVÃO, C.O. Qualidade e manejo da água da chuva na zona rural: considerações sobre o P1MC. In: MATTOS, A.; MATTOS, K.M.C. Projeto Monitoramento da evaporação e as mudanças climáticas (MEVEMUC). João Pessoa: Moura Ramos, 2014. $580 \mathrm{p}$.

COHIM, E.; ORRISCO, S.; KIERONSKI, E.B. Manejo e qualidade da água de chuva no setor urbano. In: SANTOS, D.B.; MEDEIROS, S.S.; BRITO, L.T.L; GNADLINGER, J.; COHIM, E.; PAZ, V.P.S.; GHEYI, H.R. (org.). Captação, manejo e uso de água de chuva. Campina Grande: INSA, 2015. p. 189-210. 441 p.

FONSECA, J.E. Implantação de cisternas para armazenamento de água de chuva e seus impactos na saúde infantil: uma coorte em Berilo e Chapada do Norte, Minas Gerais. 283f. Dissertação (Mestrado em Saneamento, Meio Ambiente e Recursos Hídricos) - Universidade Federal de Minas Gerais, Belo Horizonte, 2012.
FONSECA, J.E.; CARNEIRO, M.; PENA, J.L.; COLOSIMO, E.A.; SILVA, N.B.; COSTA, A.G.F.C.; MOREIRA, L.E.; CAIRNCROSS, S.; HELLER, L. Reducing Occurrence of Giardia duodenalis in Children Living in Semiarid Regions: Impact of a Large Scale Rainwater Harvesting Initiative. PLoS Neglected Tropical Diseases, v. 8, n. 6, p. e2943, 2014. https://doi.org/10.1371\%2Fjournal. pntd.0002943

GNADLINGER, J. Água de chuva no manejo integrado dos recursos hídricos em localidade semiárida: aspectos históricos, biofísicos, técnicos, econômicos e sociopolíticos. In: SANTOS, D.B.; MEDEIROS, S.S.; BRITO, L.T.L.; GNADLINGER, J.; COHIM, E.; PAZ, V.P.S.; GHEYI, H.R. Captação, manejo e uso de água de chuva. Campina Grande: INSA, 2015. p. 37-74. 441 p.

GOMES, U.A.F.; DOMĖNECH, L.; PENA, J.L.; HELLER, L.; PALMIER, L.R. A Captação de Água de Chuva no Brasil: Novos Aportes a Partir de um Olhar Internacional. Revista Brasileira de Recursos Hidricos, v. 19, n. 1, p. 7-16, 2014. https://doi.org/10.21168/rbrh.v19n1.p7-16

GOMES, U.A.F.; HELLER, L. Acesso à água proporcionado pelo programa de formação e mobilização social para convivência com o semiárido: um milhão de cisternas rurais: combate à seca ou ruptura da vulnerabilidade? Engenharia Sanitária Ambiental, Rio de Janeiro, v. 21, n. 3, p. 623-633, set. 2016 Disponível em: http://www.scielo.br/scielo.php?script=sci_arttext\&pid=S141341522016000300623\&lng=en\&nrm=iso. Acesso em: 28 out. 2016. https:// doi.org/10.1590/S1413-41522016128417

GOULD, J.; NISSEN-PETERSEN, E. Rainwater catchment systems for domestic supply: design, construction and implementation. Londres: ITDG, 2002. $356 p$

HAGEMANN, S.E. Avaliação da qualidade da água da chuva e da viabilidade de sua captação e uso. 141f. Dissertação (Mestrado do Programa de PósGraduação em Engenharia Civil) - Universidade Federal de Santa Maria, Santa Maria, 2009

INSTITUTO BRASILEIRO DE GEOGRAFIA E ESTATÍSTICA (IBGE). Censo Demográfico 2010. Brasil: IBGE, 2010. Disponível em: http://www. censo2010.ibge.gov.br/sinopse/index. php?uf=25\&dados=0. Acesso em: 21 jan. 2021. 
KWAADSTENIET, M.D.; DOBROWSKY, P.H.; DEVENTER, A.V.; KHAN, W.; CLOETE, T.E. Domestic Rainwater Harvesting: Microbial and Chemical Water Quality and Point-of-Use Treatment Systems. Water, Air, \& Soil Pollution, v. 224, p. 1629, 2013. https://doi.org/10.1007/s11270-013-1629-7

LUNA, C.F. Avaliação do impacto do Programa Um Milhão de Cisternas Rurais (PIMC) na saúde: ocorrência de diarreia no Agreste Central de Pernambuco. 207f. Tese (Doutorado em Saúde Pública) - Centro de Pesquisas Aggeu Magalhães, Fundação Oswaldo Cruz, Pernambuco, 2011.

MACHADO, T.T.V. Qualidade da água de chuva armazenada em cisternas de placas e de polietileno no semiárido do estado da Paraíba. 283f. Tese (Doutorado em Desenvolvimento e Meio Ambiente) - Universidade Federal da Paraíba, João Pessoa, 2017.

MACHADO, TT.V.; DIAS, J.T.; SILVA, T.C. Evolução e avaliação das políticas públicas para a atenuação dos efeitos da seca no semiárido brasileiro. Gaia Scientia, João Pessoa, v. 11, n. 2, p. 84-103, jul. 2017. https://doi.org/10.22478/ ufpb.1981-1268.2017v11n2.31831

MOURA, T.O.; OLIVEIRA, I.B.; MEDEIROS, Y.D.P.; CAMPOS, V.P. Analyze the quality of rain waterstoredintanksmadeof polyethyleneofruralcommunities belonging to the municipality of São Domingos (located in the Semiarid da Bahia). Journal of Engineering and Technology for Industrial Applications, v. 3, n. 10, p. 99-103, 2017. Disponível em: https://www.researchgate.net/ profile/Thamires-Moura-2/publication/317576181_ANALYSIS_OF_THE_ QUALITY_OF_RAIN_WATER_STORED_IN_POLYETHYLENE_TANKS_OF_ RURAL_COMMUNITIES_BELONGING_TO_THE_MUNICIPALITY_OF_SAO_ DOMINGOS_SEMIARIDO_BAHIANO/links/5ac660f2Of7e9bcd51931560/ ANALYSIS-OF-THE-QUALITY-OF-RAIN-WATER-STORED-IN-POLYETHYLENETANKS-OF-RURAL-COMMUNITIES-BELONGING-TO-THE-MUNICIPALITYOF-SAO-DOMINGOS-SEMIARIDO-BAHIANO.pdf. Acesso em: 21 jan. 2021. https://doi.org/10.5935/2447-0228.20170036

NÓBREGA, R.L.B.; GALVÃO, C.O.; PALMIER, L.R.; CEBALLOS, B.S.O. Aspectos Político-Institucionais do Aproveitamento de Agua de Chuva em Áreas Rurais do Semiárido Brasileiro. Revista Brasileira de Recursos Hídricos, v. 17, n. 4. p. 109-124, 2012. https://doi.org/10.21168/rbrh.v17n4.p109-124

PALHARES, J.C.P.; GUIDONI, A.L. Qualidade da água de chuva armazenada em cisterna utilizada na dessedentação de suínos e bovinos de corte. Revista Ambiente \& Água, v. 7. n. 1, p. 244-254, 2012. Disponível em: http:// www.scielo.br/pdf/ambiagua/v7n1/v7n1a19.pdf. Acesso em: 12 set. 2016. https://doi.org/10.4136/ambi-agua.822

PIVELI, R.P.; KATO, M.T. Qualidade das águas e poluição: aspectos físicoquímicos. São Paulo: Abes, 2005.

SANTANA, N.C.B. Qualidade das águas de chuva em João Pessoa-PB: estudo comparativo com padrões de qualidade para uso residencial. $83 f$. Dissertação (Mestrado em Engenharia Urbana e Ambiental) - Universidade Federal da Paraíba, João Pessoa, 2012.

SANTOS, M.J.; BOMFIM, E.O.; ARAÚJO, L.E.; SILVA, B.B. Programa um Milhão de Cisternas Rurais: Matriz Conceitual e Tecnológica. Artigo de Revisão.
Científica Ciências Exatas e Tecnológicas, Londrina, v. 8, n. 1, p. 35-43, nov. 2009.

SCHMITT, J.F.A. Adoção de inovações no combate à seca no semiárido: um estudo com os usuários de cisternas de polietileno nos municípios de Trairi-CE e Caucaia-CE. 90f. Dissertação (Mestrado Acadêmico em Administração) - Universidade Estadual do Ceará, Fortaleza, 2015.

SILVA, C.V. Qualidade da água de chuva para consumo humano armazenada em cisternas de placa. Estudo de caso: Araçuaí, MG. 136f. Dissertação (Mestrado) - Universidade Federal de Minas Gerais, Belo Horizonte, 2006.

SILVA, C.V; HELLER, L;; CARNEIRO, M. Cisternas para armazenamento de água de chuva e efeito na diarreia infantil: um estudo na área rural do semiárido de Minas Gerais. Engenharia Sanitária e Ambiental, Rio de Janeiro, v. 17, n. 4, p. 393-400, dez. 2012. Disponível em: http://www.scielo.br/scielo. php?script=sci_arttext\&pid=S1413-41522012000400006\&lng=en\&nrm=iso Acesso em: 28 out. 2016. https://doi.org/10.1590/S1413-41522012000400006

SILVA, C.V.; HELLER, L.; PENA, J.L.; FONSECA, J.E. Avaliação da presença de giárdia em crianças menores de 60 meses que consomem água de chuva armazenada em cisternas - Médio Vale do Jequitinhonha, MG. In: CONGRESSO BRASILEIRO DE ENGENHARIA SANITARIA E AMBIENTAL, 26., 2012. Anais [...]. Rio de Janeiro: Abes, 2012.

SOUZA, S.H.B.; MONTENEGRO, S.M.G.L.; SANTOS, S.M.; PESSOA, S.G.S.; NÓBREGA, R.L.B. Avaliação da qualidade da água e da eficácia de barreiras sanitárias em sistemas para aproveitamento de águas de chuva. Revista Brasileira de Recursos Hidricos, v. 16, n. 3, p. 81-93, 2011. http://dx.doi. org/10.21168/rbrh.v16n3.p81-93

TAVARES, A.C. Aspectos Físicos, Químicos e Microbiológicos da Água Armazenada em Cisternas de Comunidades Rurais no Semiárido Paraibano. 166f. Dissertação (Mestrado em Desenvolvimento e Meio Ambiente) Universidade Estadual da Paraíba, Campina Grande, 2009.

VIDAL, R.T. Agua de lluvia, agua saludable (manual de mantenimiento del sistema de captación de agua de lluvia). Proyeto de Apoyo a la Reforma del Sector Saluden Guatemala (Apresal). República de Guatemala: Comisión Europea, 2002. 108 p.

VIEIRA, M.R. Os principais parâmetros monitorados pelas sondas multiparâmetros são: $\mathrm{pH}$, condutividade, temperatura, turbidez, clorofila ou cianobactérias e oxigênio dissolvido. 2016. Disponível em: https://www. agsolve.com.br/news_upload/file/Parametros\%20da\%20Qualidade\%20 da\%20Agua.pdf. Acesso em: 26 jan. 2021.

VIRIATO, C.L. Caracterização físico-química e bacteriológica da água armazenada em cisternas no semiárido paraibano. 104f. Monografia (Especialização em Geociência e Recursos Hídricos do Semiárido) Universidade Estadual de Campina Grande, Campina Grande, 2011

XAVIER, R.P. Influência de barreiras sanitárias na qualidade da água de chuva armazenada em cisternas no semiárido paraibano. 130f. Dissertação (Mestrado em Recursos Hídricos e Saneamento) - Universidade Federal de Campina Grande, Campina Grande, 2010. 